\title{
Absolute Rate Calculations: Atom and Proton Transfers in Hydrogen-Bonded Systems**
}

\author{
Mónica Barroso, Luis G. Arnaut,* and Sebastião J. Formosinho ${ }^{[a]}$
}

We calculate energy barriers of atom- and proton-transfer reactions in hydrogen-bonded complexes in the gas phase. Our calculations do not involve adjustable parameters and are based on bond-dissociation energies, ionization potentials, electron affinities, bond lengths, and vibration frequencies of the reactive bonds. The calculated barriers are in agreement with experimental data and high-level $a b$ initio calculations. We relate the height of the barrier with the molecular properties of the reac- tants and complexes. The structure of complexes with strong hy drogen bonds approaches that of the transition state, and sub stantially reduces the barrier height. We calculate the hydrogenabstraction rates in $\mathrm{H}$-bonded systems using the transition-state theory with the semiclassical correction for tunneling, and show that they are in excellent agreement with the experimental data. $\mathrm{H}$-bonding leads to an increase in tunneling corrections at room temperature.

\section{Introduction}

The hydrogen bond plays a major role in chemistry and biology, and its impact in diverse fields, such as atmospheric chemistry ${ }^{[1]}$ and enzymatic catalysis, ${ }^{[2]}$ is widely recognized. The role of hydrogen bonds has been most appreciated for its implications in the structure and energy of molecular systems. The classical fingerprints of conventional hydrogen bonds are the decrease of the $\mathrm{H}-\mathrm{X}$ vibrational frequency, the increase of the $\mathrm{H}-\mathrm{X}$ bond length in $\mathrm{Y} \cdots \mathrm{H}-\mathrm{X}$ complexes relative to the values of the isolated bond, and the observation of $\mathrm{YX}$ distances that are smaller than the sum of the corresponding van der Waals radii. ${ }^{[3-6]}$ The role of the $\mathrm{H}$ bond in the kinetics of molecular systems also has a long and rich history, ${ }^{[7-9]}$ but only recently has it become possible to probe the reactive dynamics of $\mathrm{H}$-bonded systems with adequate theoretical frameworks and experimental tools. ${ }^{[10-12]}$

One of the earliest models to quantitatively relate $\mathrm{O}-\mathrm{H} \cdots \mathrm{O}$ bond strengths to vibrational frequencies and bond lengths was formulated by Lippincott and Schroeder (LS). ${ }^{[13,14]}$ The LS potential provides a rich chemical insight into the nature of $\mathrm{H}$ bonds, but it cannot be used to trace the changes in potential resulting from simultaneous $\mathrm{H}-\mathrm{O}$ and $\mathrm{O}$-.... $\mathrm{O}$ motion in a particular $\mathrm{H}$ bond. In fact, following the LS potential, as the $\mathrm{O}$-.... O atoms approach, all $\mathrm{H}$ bonds contract to the symmetrical form until the strongest $\mathrm{O} \cdots \mathrm{H} \cdots \mathrm{O}$ bond is formed with an $\mathrm{O} \cdots \cdots \mathrm{O}$ distance of about $2.45 \AA$. Applications and modifications of the LS potential have appeared, ${ }^{[15-18]}$ but the available semiempirical potentials remain inadequate for the calculation of $\mathrm{H}$-atom or proton-transfer barriers.

A quantitative description of the energy of $\mathrm{H}$-bonded systems as a function of the $\mathrm{Y} \cdots \mathrm{H}-\mathrm{X}$ geometry emerged with the refinement of $a b$ initio calculations. ${ }^{[19-27]}$ Sufficiently high-level molecular orbital calculations may provide good numerical estimates for the energy barriers of $\mathrm{H}$-atom and proton transfers in $\mathrm{H}$-bonded complexes. However, they do not offer clear explanations of why barrier heights differ from one system to another.

Herein, we have examined the effect of the molecular structure and binding energies of the $\mathrm{H}$-bonded complexes on the rates of $\mathrm{H}$-atom transfers of the type: $\mathrm{Y}+\mathrm{HX} \rightarrow \mathrm{Y} \cdots \mathrm{HX} \rightarrow$ $\mathrm{YH} \cdots \mathrm{X} \rightarrow \mathrm{YH}+\mathrm{X}$ and on the barriers of the proton transfers. Our calculations employ the interacting-state model (ISM) ${ }^{[28]}$ and the LS potential to calculate the energy barriers, and the transition-state theory with the semiclassical correction (sc-TST) for tunneling $^{[29]}$ to calculate the rates. These theoretical models were selected because they offer a clear relationship between the properties of the reactants, the barrier heights, and the rates constants. Moreover, they do not involve the fitting of any parameters to the kinetic data. The present calculations generalize, to H-bonded systems, the ISM absolute rate calculations presented for atom-transfer reactions in the gas phase (Part I of this work). ${ }^{[28]}$ The calculation of proton-transfer barriers relates the present approach to earlier studies of protontransfer reactions with ISM. ${ }^{[30-32]}$

\section{Results and Discussion}

\subsection{Reaction Coordinate}

The performance of the LS potential in relating $\mathrm{H}$-bond binding energies $\left(D_{\mathrm{XY}}\right)$ to $\mathrm{YX}$ equilibrium distances $\left(I_{\mathrm{XY}}^{*}\right)$ can be assessed from the large variety of $\mathrm{Y} \cdot \mathrm{.H}-\mathrm{X}$ complexes presented in Table 1.

Lippincott and Schroeder originally calibrated their potential using experimental $\mathrm{H}$-bond dissociation energies and a $3 \mathrm{RT} / 2$ correction for the loss of degrees of freedom in the formation of the $\mathrm{H}$ bond. When we employ electronic dissociation energies $\left(D_{\mathrm{e}}\right)$, we see that the calibration has a tendency to under-

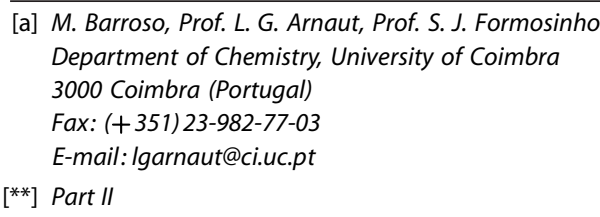


Table 1. Bond lengths $[\AA], \mathrm{H}$-bond binding energies $\left[\mathrm{kcal} \mathrm{mol}^{-1}\right]$, and energy barriers $\left[\mathrm{kcal} \mathrm{mol}^{-1}\right]$ of symmetrical hydrogen-bonded systems. ${ }^{[a]}$

\begin{tabular}{|c|c|c|c|c|c|}
\hline & $I_{\mathrm{XY}}^{*}$ & $I_{\mathrm{XY}}^{*}(\mathrm{LS})$ & $D_{\mathrm{XY}}$ & $\Delta V^{i}$ ab initio & $\Delta V^{\prime}(\mathrm{LS}-\mathrm{ISM})^{[\mathrm{b}]}$ \\
\hline$\left[\mathrm{NH}_{3}\right]_{2}$ & $3.337^{[33]}$ & 2.918 & $\{2.9\}^{[34]}$ & & \\
\hline$\left[\mathrm{H}_{2} \mathrm{O}\right]_{2}$ & $2.912^{[26]}$ & 2.688 & $\{5.0\}^{[26]}$ & & \\
\hline$[\mathrm{HO} \cdots \mathrm{HOH}]$ & $2.896^{[35]}$ & 2.643 & $\{5.7\}^{[36]}$ & $10.3^{[37]}$ & 9.1 \\
\hline$[\mathrm{HF}]_{2}$ & $2.72^{[38]}$ & 2.669 & $\{4.5\}^{[26]}$ & & \\
\hline$[\mathrm{F} \cdots \mathrm{HF}]$ & $3.04^{[39]}$ & 2.848 & $\{1.4\}^{[39]}$ & & \\
\hline$[\mathrm{HCl}]_{2}$ & $3.746^{[40]}$ & 3.642 & $\{1.95\}^{[26]}$ & & \\
\hline$\left[\mathrm{CH}_{3} \mathrm{OH}\right]_{2}$ & $2.873^{[41]}$ & 2.565 & $3.2^{[42]}$ & & \\
\hline$[\mathrm{Cl} \cdots \mathrm{HCl}]$ & $3.98^{[43]}$ & 3.684 & $0.94^{[43]}$ & $5.3^{[44]}$ & 7.2 \\
\hline$\left[\mathrm{SH}_{2}\right]_{2}$ & $4.08^{[45]}$ & 3.743 & $1.4^{[46]}$ & & \\
\hline$\left[\mathrm{H}^{-} \cdots \mathrm{H}_{2}\right]$ & $3.295^{[47]}$ & 2.908 & $\{1.10\}^{[47]}$ & $\{10.55\}^{[48]}$ & $\{10.10\}$ \\
\hline$\left[\mathrm{CH}_{3}{ }^{-} \cdots \mathrm{CH}_{4}\right]$ & $3.72^{[22]}$ & 3.408 & $-0.9^{[22]}$ & $\{13.31\}^{[23]}$ & $\{16.68\}$ \\
\hline$\left[\mathrm{HC} \equiv \mathrm{C}^{-} \cdots \mathrm{HC} \equiv \mathrm{CH}\right]$ & $3.237^{[24]}$ & 2.844 & $-10.6^{[24]}$ & $3.8^{[24]}$ & 4.43 \\
\hline$\left[\mathrm{N} \equiv \mathrm{C}^{-} \ldots \mathrm{HC} \equiv \mathrm{N}\right]$ & $3.097^{[24]}$ & 2.715 & $-18.7^{[24]}$ & $2.8^{[24]}$ & 3.03 \\
\hline$\left[\mathrm{H}_{2} \mathrm{~N}^{-} \ldots \mathrm{NH}_{3}\right]$ & $2.91^{[22]}$ & 2.584 & $-12.0^{[49]}$ & $6.29^{[23]}$ & 4.79 \\
\hline$\left[\mathrm{HO}^{-} \ldots \mathrm{H}_{2} \mathrm{O}\right]$ & $2.415^{[50]}$ & 2.335 & $-27^{[49]}$ & $0.4^{[23]}$ & 0 \\
\hline$\left[\mathrm{SiH}_{3}{ }^{-} \cdots \mathrm{SiH}_{4}\right]$ & & & $0^{[c]}$ & $16.28^{[23]}$ & 17.17 \\
\hline$\left[\mathrm{H}_{2} \mathrm{P}^{-} \ldots \mathrm{PH}_{3}\right]$ & $4.154^{[22]}$ & 3.807 & $-3.3^{[22]}$ & $4.14^{[23]}$ & 5.55 \\
\hline$\left[\mathrm{HS} \cdots \mathrm{SH}_{2}\right]^{-}$ & $3.545^{[22]}$ & 3.283 & $-13.2^{[49]}$ & $1.5^{[23]}$ & 2.51 \\
\hline$[\mathrm{F} \cdots \mathrm{HF}]^{-}$ & $2.27^{[51]}$ & 2.150 & $-48.5^{[49]}$ & $0^{[22]}$ & 0 \\
\hline$[\mathrm{Cl} \cdots \mathrm{HCl}]^{-}$ & $3.14 \pm 0.02^{[52]}$ & 3.052 & $-24^{[49]}$ & $0^{[23]}$ & 0 \\
\hline$[\mathrm{Br} \cdots \mathrm{HBr}]^{-}$ & $3.35 \pm 0.02^{[53]}$ & 3.347 & $-20.6^{[49]}$ & $0^{[23]}$ & 0 \\
\hline$[\mid \cdots \mathrm{HII}]^{-}$ & $3.80^{[54]}$ & 3.749 & $-17.0^{[49]}$ & & 0 \\
\hline
\end{tabular}

[a] $\mathrm{H}$-Bond binding energies or, more exactly, experimental enthalpies of $\mathrm{H}$-bond formation or theoretical bond-dissociation energies at $0 \mathrm{~K}$. The values in brackets are electronic energies $\left(D_{\mathrm{e}}\right)$, without ZPE. The values of $I_{x y}^{*}$ were selected from experimental or high-level ab initio calculations for the XY distance in $\mathrm{X} \cdots \mathrm{H}-\mathrm{Y}$ complexes. [b] Atom-transfer barriers are relative to the isolated reactants; for the values of $m$ see Table 2. Protontransfer barriers were calculated with $m=2$ except for systems $\left[\mathrm{H}^{-} \ldots \mathrm{H}_{2}\right],\left[\mathrm{CH}_{3}{ }^{-} \ldots \mathrm{CH}_{4}\right]$, and $\left[\mathrm{SiH}_{3}{ }^{-} \ldots \mathrm{SiH}_{4}\right]$ where $m=1$. [c] The complex formed is not hydrogen-bonded.

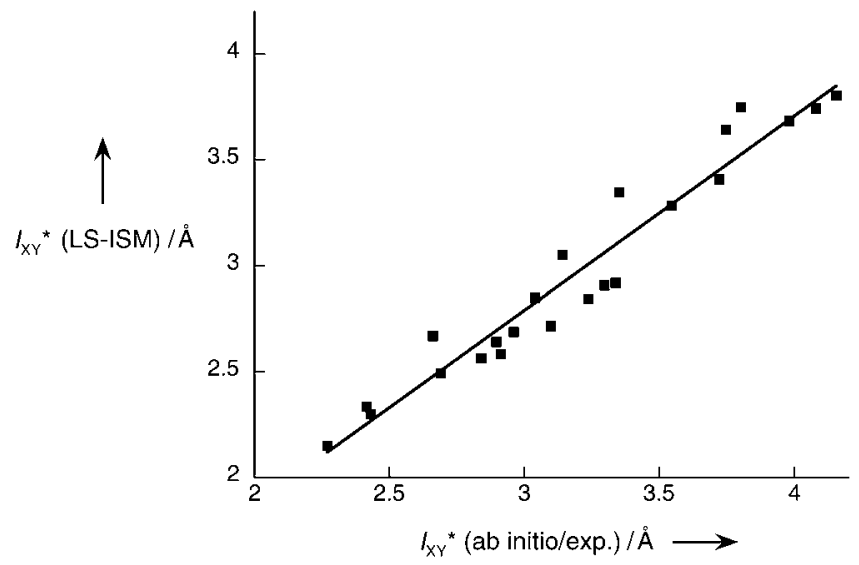

Figure 1. Correlation between the YX equilibrium distances, $I_{X Y}^{*}$ calculated by the LS potential and the experimental or ab initio data for the same $\mathrm{H}$ bond.

estimate $I_{\mathrm{XY}}^{*}$. However, Figure 1 shows that the original LS potential is still appropriate to relate $I_{\mathrm{XY}}^{*}$ to $D_{\mathrm{XY}}$ and we did not change its parameters. These differences are partly offset in the calculation of the $\mathrm{H}$-atom transfer rates discussed below because we employed experimental $\mathrm{H}$-bonding energies and zero-point energy corrections in such calculations.

It is more difficult to assess the quality of the LS potential in predicting the vibrational frequency of the $\mathrm{H}$-bond stretching $\left(\omega_{\mathrm{XY}}\right)$, because very few experimental data are available. However, it is encouraging to see that we calculate $\omega_{0 O}=227 \mathrm{~cm}^{-1}$ for the $\left(\mathrm{H}_{2} \mathrm{O}\right)_{2}$ dimer, whereas the experimental value is $150 \mathrm{~cm}^{-1[55-57]}$ and the best ab initio estimate is $158 \mathrm{~cm}^{-1}$. ${ }^{[58]}$ The observed 00 frequency in ice I is $220 \mathrm{~cm}^{-1} \cdot{ }^{[3]}$ This frequency increases to $1063 \mathrm{~cm}^{-1}$ in the $\mathrm{HO}^{-}$... $\mathrm{H}-\mathrm{OH}$ complex, which compares very well with the value of $1082 \mathrm{~cm}^{-1}$ reported in the literature. ${ }^{[59]} \mathrm{A}$ poorer agreement is found between the LS and ab initio $\omega_{\mathrm{NN}}$ frequencies of the $\left(\mathrm{NH}_{3}\right)_{2}$ dimer $(212$ and $103 \mathrm{~cm}^{-1}$, respectively) ${ }^{[60]}$ and for the (HF) dimer (197 and $160 \mathrm{~cm}^{-1}$, respectively).

The parameters $D_{\mathrm{XY}} I_{\mathrm{XY}}^{*}$ and $\omega_{\mathrm{XY}}$ given by the LS potential can be used to construct a Morse curve for the $X Y$ bond. This curve describes the approach of $\mathrm{Y}$ to $\mathrm{HX}$ in the formation of the $\mathrm{Y} \cdots \mathrm{H}-\mathrm{X}$ precursor complex, and the separation of $X$ from $\mathrm{YH}$ in the dissociation of the $\mathrm{Y}-\mathrm{H} \cdots \mathrm{X}$ successor complex. However, as mentioned in the Introduction, the LS potential does not provide information on the energy changes associated with the transformation of $\mathrm{Y}$... $\mathrm{H}-\mathrm{X}$ into $\mathrm{Y}-\mathrm{H}$...X.

We overcome this insufficiency of the LS potential by relating the bond lengths in the $\mathrm{Y} \cdots \mathrm{H}-\mathrm{X}$ and $\mathrm{Y}-\mathrm{H} \cdots \mathrm{X}$ complexes to the corresponding bond orders ${ }^{[28]}$ [Eqs. (1a) and (1b)]:

$$
\begin{aligned}
& n^{*}{ }_{\mathrm{HX}}=\exp \left[-\frac{I_{\mathrm{HX}}^{*}-I_{\mathrm{HX}, \mathrm{eq}}^{*}}{a^{\prime}\left(I_{\mathrm{HX}, \mathrm{eq}}+I_{\mathrm{HY}, \mathrm{eq}}^{*}\right)}\right] \\
& n^{*}{ }_{\mathrm{HY}}=\exp \left[-\frac{I_{\mathrm{HY}}^{*}-I_{\mathrm{HY}, \mathrm{eq}}^{*}}{a^{\prime}\left(I_{\mathrm{HX}, \mathrm{eq}}^{*}+I^{*}{ }_{\mathrm{HY}, \mathrm{eq}}\right)}\right]
\end{aligned}
$$

where $a^{\prime}=0.182$ is a scaling constant. These equations are a generalization of the Pauling relation, ${ }^{[61]}$ and have been used to construct reaction coordinates for atom transfers. ${ }^{[28,62,63]}$ Figure 2 shows that the total bond order $\left(n_{\mathrm{HX}}{ }^{*}+n_{\mathrm{HY}}{ }^{*}\right)$ of the systems with double-well potential energy surfaces studied here is approximately conserved. This is not unexpected in view of the fact that the formation of the conventional $\mathrm{H}$ bonded complex $\mathrm{Y} \cdots \mathrm{H}-\mathrm{X}$ is accompanied by the elongation of the $\mathrm{HX}$ bond. The values of $n_{\mathrm{HX}}{ }^{*}$ and $n_{\mathrm{HY}}{ }^{*}$ tend to 0.5 with increasing strength of the $\mathrm{H}$ bond.

The bond orders of the $\mathrm{H}$ bonds in precursor and successor symmetrical complexes should always be under 0.5. However, we observe that, in strongly bonded $(\mathrm{X} \cdots \mathrm{H}-\mathrm{X})^{-}$complexes where $\mathrm{X}=\mathrm{F}, \mathrm{Cl}, \mathrm{Br}, \mathrm{I}$, or $\mathrm{OH}$, the $\mathrm{X} \cdots \mathrm{H}$ bond orders are slightly 


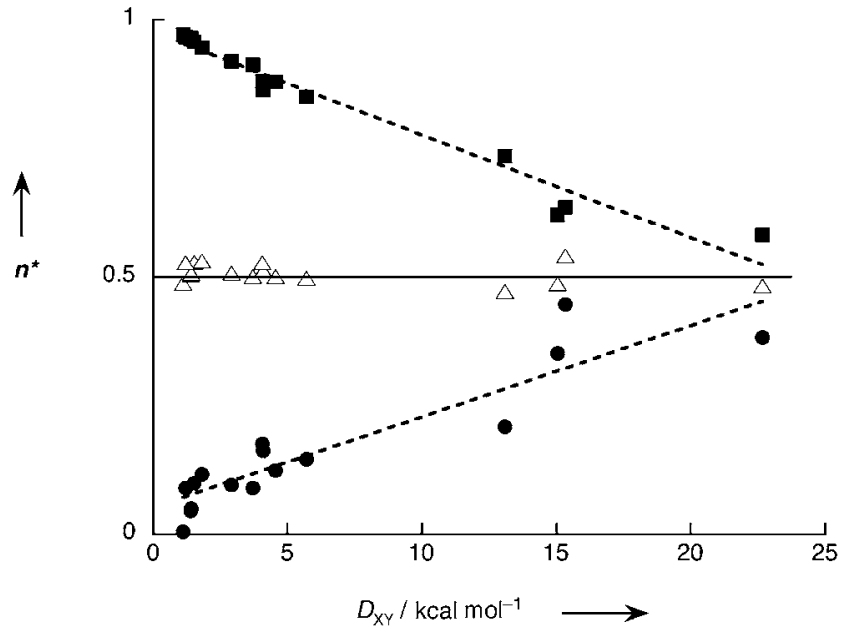

Figure 2. Conservation of the total bond order in H-bonded complexes, shown as the bond orders of the $H X$ and $H Y$ bonds in the precursor complex $\left[\mathrm{n}^{*}{ }_{H X}(\mathbf{O})\right.$, $\mathrm{n}_{H Y}^{*}(\mathbf{\square})$ ] and their semisum $(\triangle)$.

over 0.5 . This effectively means that the covalency of the $X \cdots \cdot \mathrm{H}$ bond cannot be distinguished from that of the HX bond, and that the complex is best described as a symmetrical ion. In such cases, we have single-well potential energy curves with no internal barrier for proton transfers. This issue will be further discussed in the section on proton-transfer barriers.

The observation that $n_{\mathrm{HX}}{ }^{*}+n_{\mathrm{HY}}{ }^{*} \approx 1$ in $\mathrm{H}$-bonded complexes is another manifestation of the conservation of the total bond order originally proposed by Johnston for hydrogen-transfer reactions. ${ }^{[64,65]}$ This property is also incorporated in the reaction coordinate of $\mathrm{ISM}^{[62,63,66]}$ and was recently shown to provide good estimates for atom-transfer rates. ${ }^{[28]}$ The bond order of the $\mathrm{YH}$ bond increases from zero in the isolated reactants to unity in the isolated products, and was selected as the reaction coordinate $n$. Concomitant changes occur in the HX bond order. These limits have to be modified for atom transfers in $\mathrm{H}$ bonded complexes. Now the central barrier increases from the minimum of the precursor complex, where the bond order is $n_{\mathrm{HX}}{ }^{*}$, and vanishes in the minimum of the successor complex, where the bond order is $n_{\mathrm{HY}}{ }^{*}$.

LS and ISM are complementary potential functions, because the former provides a good description of the stabilization of the $\mathrm{Y}+\mathrm{HX}$ system when a $\mathrm{H}$ bond is formed, whereas the latter accounts for the energy barrier found along the reaction coordinate. Thus, the reaction path of atom-abstraction reactions in $\mathrm{H}$-bonded systems can be conveniently divided into three parts. The energy of the system as the two reactants approach from infinity to the equilibrium geometry of the $\mathrm{H}$ bonded precursor complex is given by Equation (2):

$V(n)=V_{\mathrm{XY}}(n)-D_{\mathrm{XY}} \quad$ for $n<n_{\mathrm{HX}}^{*}$

where $V_{X Y}(n)$ is the Morse curve, built with the parameters $D_{X Y}$ $I_{X Y}{ }^{*}$, and $\omega_{X Y}$ of the LS potential, and is calculated for each $X Y$ distance along the reaction coordinate under the assumption that $n_{\mathrm{HX}}{ }^{*}+n_{\mathrm{HY}}{ }^{*}=1$. In the region between the precursor and successor complexes, the energy is given by a combination of
ISM and LS potentials, which are defined as in Equation (3):

$$
\begin{aligned}
& V(n)=(1-j) V_{\mathrm{HX}}(1-j)+j V_{\mathrm{HY}}(j)+k \Delta V^{0}+V_{\mathrm{XY}}(n)-D_{\mathrm{XY}} \\
& \text { for } n_{\mathrm{HX}}{ }^{*}<n<n_{\mathrm{HY}}{ }^{*}
\end{aligned}
$$

where $V_{\mathrm{HX}}$ and $V_{\mathrm{HY}}$ are the Morse curves of the $\mathrm{HX}$ and $\mathrm{HY}$ bonds, respectively, and $\Delta V^{\circ}=D_{\mathrm{HX}}-D_{\mathrm{HY}}$ is the classical reaction energy. The continuity of the reaction coordinate is obtained with the linear transformations [Eqs. (4a), (4b), and (4c)]:

$k=\left(n-n^{*}{ }_{\mathrm{HX}}\right) /\left(1-n^{*}{ }_{\mathrm{HX}}-n^{*}{ }_{\mathrm{HY}}\right)$

$j=n-n_{\mathrm{HX}}^{*} \quad$ for $n<n^{\neq}$

$j=n-\left(1-n^{*}{ }_{\mathrm{HY}}\right) \quad$ for $n>n^{*}$

and $n^{*}$ is the transition-state bond order. Finally, as the products separate, the energy is given by Equation (5):

$V(n)=V_{\mathrm{XY}}(n)-D_{\mathrm{XY}} \quad$ for $n>1-n_{\mathrm{HY}}^{*}$

The Morse curves employed in the ISM reaction path are expressed in terms of bond orders rather than bond extensions, ${ }^{[28]}$ as shown in Equations (6a) and (6b):

$$
\begin{aligned}
& V_{\mathrm{HX}}(1-j)=D_{\mathrm{HX}}\left\{1-\exp \left[\beta_{\mathrm{HX}} a^{\prime}\left(I_{\mathrm{HX}, \text { eq }}+I_{\mathrm{HY}, \mathrm{eq}}\right) \ln (1-j) / m\right]\right\} \\
& V_{\mathrm{HY}}(j)=D_{\mathrm{HY}}\left\{1-\exp \left[\beta_{\mathrm{HY}} a^{\prime}\left(I_{\mathrm{HX}, \text { eq }}+I_{\mathrm{HY}, \mathrm{eq}}\right) \ln (j) / m\right]\right\}
\end{aligned}
$$

and include the electrophilicity index of Parr [Eq. (7)] to account for the increase in electronic density at the transition state ${ }^{[67]}$

$m=\frac{I_{\mathrm{p}}+E_{\mathrm{A}}}{I_{\mathrm{p}}-E_{\mathrm{A}}}$

where $I_{\mathrm{P}}$ is the ionization potential and $E_{\mathrm{A}}$ the electron affinity of $\mathrm{X}$ or $\mathrm{Y}$.

Figure 3 shows that the LS-ISM and ab initio reaction coordinates for $\mathrm{OH}+\mathrm{HCl}$ and $\mathrm{OH}+\mathrm{H}_{2} \mathrm{O}$ exchanges are in good agreement, and suggests that LS-ISM potentials can be employed to calculate both barrier heights and reaction rates of $\mathrm{H}$-atom transfers in $\mathrm{H}$-bonded complexes.

\subsection{Hydrogen-Atom Transfer Rates}

Our main interest is to calculate the rates of chemical reactions using the properties of reactants and products. This can be achieved in H-bonded complexes using the LS-ISM energy barriers together with the transition-state theory. The calculated rates can be further refined including semiclassical tunneling corrections. The inclusion of zero-point energy and tunneling corrections along the ISM reaction coordinate was recently discussed. These corrections were employed in the calculation of 100 activation energies and 50 room-temperature reaction rates, in good agreement with the experimental data, ${ }^{[28]}$ and were also used in this work. The present calculations differ 


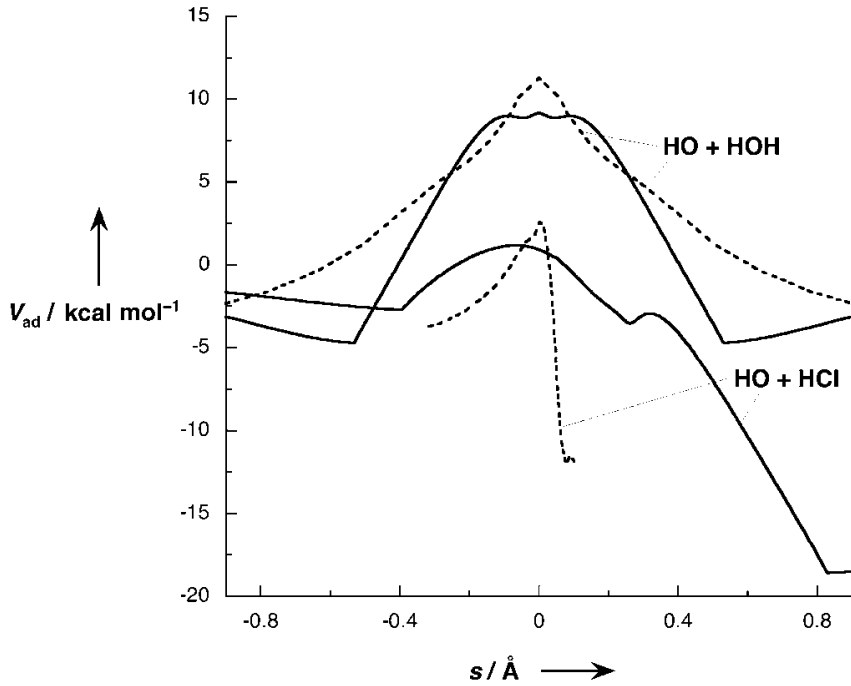

Figure 3. Ab initio ${ }^{[36,68]}$ (--.--) and LS-ISM (-) classical energy profiles for $\mathrm{OH}+\mathrm{HCl}$ and $\mathrm{OH}+\mathrm{H}_{2} \mathrm{O}$ hydrogen exchanges. The ab initio results for $\mathrm{OH}+\mathrm{HCl}$ were scaled to reproduce the recommended rate constants over a wide temperature range.

from earlier work by the inclusion of $\mathrm{H}$-bonded complexes in the reaction coordinate. Table 2 shows the data employed in the calculations and compares the room-temperature rates with experimental values. The binding energies of symmetric $\mathrm{H}$-bonded complexes, $D_{\mathrm{xy}}$, were taken as the average of $D_{\mathrm{xx}}$ and $D_{Y Y}$. The binding energies in Table 2 are bond-dissociation energies at $0 \mathrm{~K}\left(D_{0}\right)$ and are lower than the corresponding values in Table 1 by the zero-point energy of the complex.

In Figure 4, we compare the LS-ISM/sc-TST rate constants of several halogen atom-molecule complexes with experimental results. A similar comparison is presented in Figure 5 for hydroxyl radical-molecule complexes. The calculated rates are within one order of magnitude of the experimental rates. The remarkable quality of the calculated rates and the clear relation between the molecular properties of reactants and the energy barriers provided by ISM offer the opportunity to discuss the molecular factors that control $\mathrm{H}$-abstraction rates.

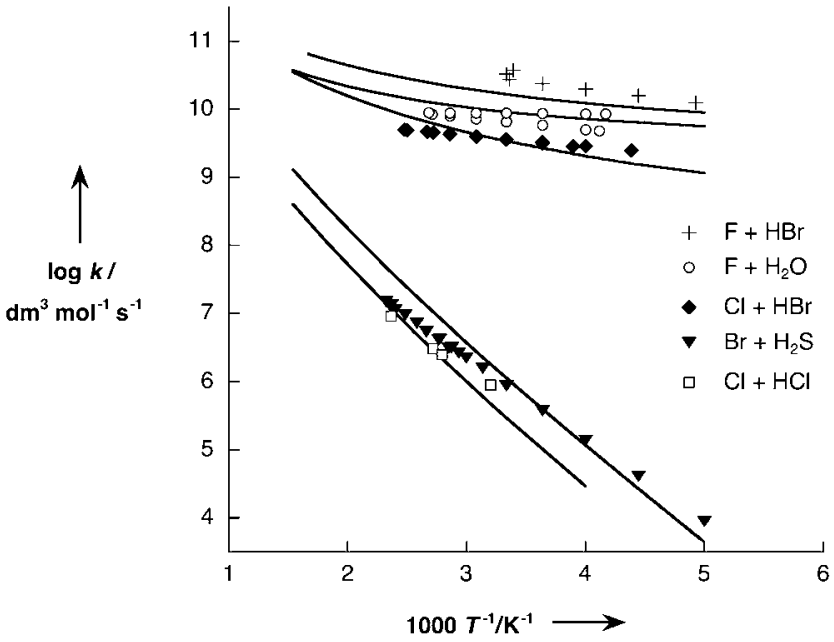

Figure 4. Experimental ${ }^{[69]}$ (symbols) and LS-ISM/sC-TST ( $\longrightarrow$ ) rate constants of hydrogen exchange in halogen atom-molecule complexes.

The rates of $\mathrm{H}$-atom abstractions by the hydroxyl radical increase with the exothermicity of the reactions, $\Delta H$, as expected from the Bell-Evans-Polanyi relationship (BEP) [Eq. (8)]:

$E_{\mathrm{a}}=\alpha \Delta H+E_{\mathrm{a}}^{0}$

and the Marcus cross-relation [Eq. (9)]:

$E_{\mathrm{a}}=E_{\mathrm{a}}^{0}\left\{1+\left[\Delta H /\left(4 E_{\mathrm{a}}^{0}\right)\right]\right\}^{2}$

where $\alpha$ is a constant and $E_{\mathrm{a}}^{0}$ is an intrinsic barrier. This trend is not strictly followed by the corresponding abstractions by halogen atoms. The $\mathrm{Br}+\mathrm{H}_{2} \mathrm{~S}$ reaction is endothermic by $3.6 \mathrm{kcal} \mathrm{mol}^{-1}$, but is faster than the $\mathrm{Cl}+\mathrm{HCl}$ exchange. This inversion of the kinetics relative to the thermodynamics can be assigned to the electronic factor. The value of $m$ increases from 1.77 to 1.95 because the $\mathrm{H}_{2} \mathrm{~S}$ has a lower ionization potential than $\mathrm{Cl}$, and the barrier is reduced.

The ratio of the rates of the symmetrical $\mathrm{OH}+\mathrm{H}_{2} \mathrm{O}$ and $\mathrm{Cl}+$ $\mathrm{HCl}$ hydrogen exchanges is approximately equal to that of the pre-exponential factors expected for atom + molecule versus diatom + molecule reactions, that is, about nine. This superficial analysis suggests that the barriers of the two reactions are identical. However, LS-ISM calculations show that the vibrationally adiabatic barrier is $9.1 \mathrm{kcal} \mathrm{mol}^{-1}$ for the $\mathrm{OH}+\mathrm{H}_{2} \mathrm{O}$ exchange, but only $7.2 \mathrm{kcal} \mathrm{mol}^{-1}$ for the $\mathrm{Cl}+\mathrm{HCl}$ exchange. At $300 \mathrm{~K}$, the later exchange should be faster by a factor of 24 , but the semiclassical tunneling correction operates in the opposite direction. At this temperature, 


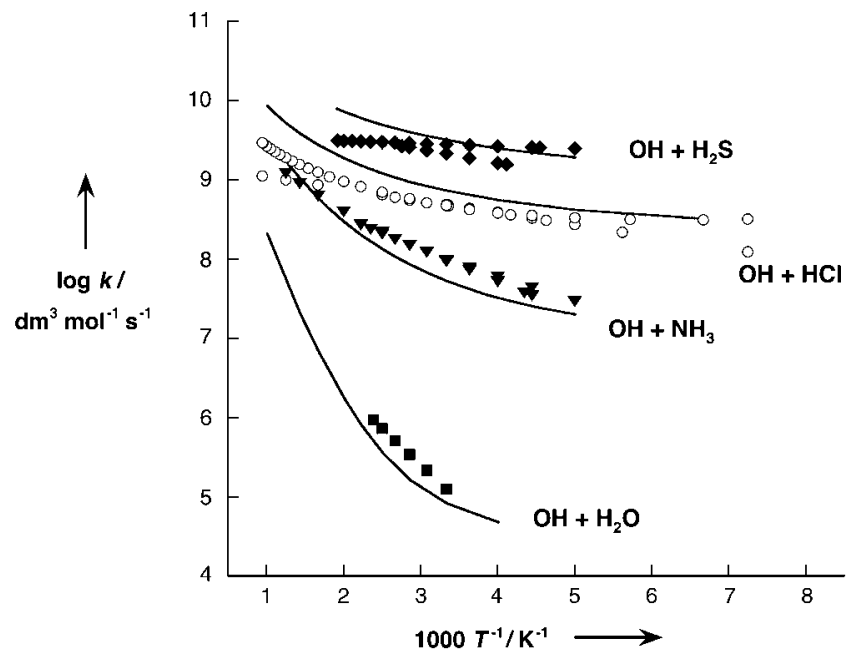

Figure 5. Experimental ${ }^{[69]}$ (symbols) and LS-ISM/SC-TST (-) rate constants of hydrogen exchange in hydroxyl radical-molecule complexes.

the tunneling correction is 112 for the first and 1.9 for the latter exchange. The absolute rate calculations for the $\mathrm{OH}+$ $\mathrm{H}_{2} \mathrm{O}$ and $\mathrm{Cl}+\mathrm{HCl}$ exchanges are in excellent agreement with the experimental rates. The extraordinary room-temperature tunneling correction of the $\mathrm{OH}+\mathrm{H}_{2} \mathrm{O}$ exchange suggests that a significant kinetic isotope effect (KIE) should be present. In fact, we calculate $1.4 \times 10^{3} \mathrm{~mol}^{-1} \mathrm{dm}^{3} \mathrm{~s}^{-1}$ for the rate of the $\mathrm{OH}+\mathrm{D}_{2} \mathrm{O}$ exchange at $300 \mathrm{~K}$, in agreement with the experimental upper limit of $3.0 \times 10^{4} \mathrm{~mol}^{-1} \mathrm{dm}^{3} \mathrm{~s}^{-1}$. On the other hand, the $\mathrm{KIE}$ of the $\mathrm{Cl}+\mathrm{HCl}$ exchange is $8.6 \pm 1.1$ at $312.5 \mathrm{~K}$, and we calculate 8.3 at this temperature. It is interesting to calculate the rate of the $\mathrm{OH}+\mathrm{H}_{2} \mathrm{O}$ exchange, without the formation of a precursor complex, to understand the effect of hydrogen bonding in this reaction. In the absence of $\mathrm{H}$ bonding, the vibrationally adiabatic barrier height increases to $11.1 \mathrm{kcal}$ $\mathrm{mol}^{-1}$, and the tunneling correction decreases to 3.6 at $300 \mathrm{~K}$. As a result, the calculated rate is one thousand times slower. Hydrogen bonding leads to a thinner barrier and to much larger tunneling corrections, which is the most important reason why the $\mathrm{H}$ transfers in $\mathrm{H}$-bonded systems tend to be faster.

Enhanced tunneling due to hydrogen bonding may not prevail over other molecular factors. For example, $\mathrm{H}$ abstraction in the $\mathrm{HO}+\mathrm{CH}_{3} \mathrm{OH}$ system may occur from the $\mathrm{CH}$ or $\mathrm{HO}$ bonds. The $\mathrm{CH}$ bond abstraction does not involve hydrogen bonding and, the $\mathrm{OH}$ bond abstraction was calculated with $D_{\mathrm{XY}}=3 \mathrm{kcal}$ $\mathrm{mol}^{-1}$. We obtained a branching ratio for $\mathrm{CH}_{3} \mathrm{O}$ formation, $\varphi=$ $k_{\mathrm{o}} /\left(k_{\mathrm{O}}+k_{\mathrm{C}}\right)$, of 0.41 at $298 \mathrm{~K}$ and 0.25 at $393 \mathrm{~K}$. The observed branching ratios are $\varphi=0.11 \pm 0.03$ and $0.22 \pm 0.07$ at 298 and $393 \mathrm{~K}$, respectively. ${ }^{[72]}$ The tunneling correction of 17 at $298 \mathrm{~K}$ is likely to be an upper limit. The branching ratio of the classical rates is 0.07 both at 298 and $393 \mathrm{~K}$. The related $\mathrm{Cl}+\mathrm{CH}_{3} \mathrm{OH}$ reaction appears to occur exclusively through $\mathrm{CH}$ abstraction. The calculated rate for $\mathrm{CH}$ abstraction at $300 \mathrm{~K}, 2.1 \times$ $10^{10} \mathrm{~mol}^{-1} \mathrm{dm}^{3} \mathrm{~s}^{-1}$, is more than four orders of magnitude higher than the calculated $\mathrm{OH}$ abstraction rate. This is in very good agreement with the observed rate, $3.3 \times$
$10^{10} \mathrm{~mol}^{-1} \mathrm{dm}^{3} \mathrm{~s}^{-1}$, and with the lack of products originated from $\mathrm{OH}$ abstraction. It is interesting to note that, although the $\mathrm{Cl}+\mathrm{CH}_{3} \mathrm{OH}$ reaction is less exothermic than the $\mathrm{HO}+$ $\mathrm{CH}_{3} \mathrm{OH}$ reaction (the vibrationally adiabatic reaction energies are $\Delta V_{\mathrm{ad}}^{0}=-6$ and $-22 \mathrm{kcalmol}^{-1}$, respectively), it is much faster and much more selective. The relative rates of these reactions challenge three widely used principles that relate activation energies to reaction energies: the BEP relationship, the Marcus cross-relation, and the reactivity-selectivity principle. These thermodynamic models of reactivity are curve-crossing models that appreciate only the effect of the reaction energy. However, the electronic factors play a major role in determining the relative rates of these reactions, because the $\mathrm{HO}+$ $\mathrm{CH}_{3} \mathrm{OH} \rightarrow \mathrm{H}_{2} \mathrm{O}+\mathrm{CH}_{2} \mathrm{OH}$ exchange has a relatively low electrophilicity index, $m=1.6$, when compared with that of the $\mathrm{Cl}+$ $\mathrm{CH}_{3} \mathrm{OH} \rightarrow \mathrm{HCl}+\mathrm{CH}_{2} \mathrm{OH}$ exchange, $m=2.8$. This difference is due to the electron affinities of $\mathrm{OH}$ and $\mathrm{Cl}$. Moreover, the methoxy radical has a higher ionization potential than the hydroxymeth$\mathrm{yl}$ radical, and $m$ decreases from 1.6 to 1.4 when the hydroxyl radical attacks the $\mathrm{OH}$ rather than the $\mathrm{CH}$ bond. In the chlorine-atom attack, the corresponding decrease is from 2.8 to 2.0. Such a significant decrease in $m$ increases the barrier by $2.7 \mathrm{kcalmol}^{-1}$ and contributes to the selectivity of the $\mathrm{Cl}$ attack. Anderson and co-workers also noticed the dependence of atom-transfer rates on the ionization potential and electron affinity of the reacting radicals and explained it as the ability to stabilize an initial charge imbalance at the transition state as the new bond is formed and the old one is broken. ${ }^{[73]}$ The poor selectivity of the $\mathrm{OH}+\mathrm{CH}_{3} \mathrm{OH}$ reaction is also related to the strength of the $\left(\mathrm{CH}_{3} \mathrm{OH} \cdots \mathrm{OH}\right) \mathrm{H}$ bond. The $\mathrm{OH}$ abstraction rate is one hundred times smaller when calculated in the absence of $\mathrm{H}$ bonding.

The LS-ISM reaction coordinate can also rationalize the branching ratio of the $\mathrm{Cl}+\mathrm{HOCl}$ reaction. Both the $\mathrm{Cl}$ - and $\mathrm{H}$ atom abstractions have similar electronic factors, $m \approx 2$, but the formation of the $\mathrm{HCl}+\mathrm{OCl}$ products, $\Delta \mathrm{V}_{\mathrm{ad}}^{0}=$ $-9.1 \mathrm{kcalmol}^{-1}$, is more exothermic than that of the $\mathrm{Cl}_{2}+\mathrm{HO}$ products, $\Delta \mathrm{V}_{\mathrm{ad}}^{0}=-1.9 \mathrm{kcal} \mathrm{mol}^{-1}$. Additionally, Table 1 suggests $D_{\mathrm{XY}} \approx 2 \mathrm{kcal} \mathrm{mol}^{-1}$ for the $(\mathrm{Cl} \cdots \mathrm{HOCl})$ complex, whereas G3//MP2 calculations give a binding energy of $1.85 \mathrm{kcal} \mathrm{mol}^{-1}$ for the $(\mathrm{Cl} \cdots \mathrm{ClOH})$ complex. ${ }^{[7]}$ The thermodynamics of the reactions, the binding energies of the precursor complexes, and the tunneling corrections favor the $\mathrm{H}$ abstraction. However, the experimental branching ratio for $\mathrm{Cl}_{2}$ formation is $\varphi=0.96 \pm 0.05$ at $298 \mathrm{~K}^{[75]}$ and the $\mathrm{Cl}$ abstraction is dominant. LS-ISM/sc-TST calculations of $\mathrm{Cl}$ and $\mathrm{H}$ abstraction rates at $298 \mathrm{~K}$, using the binding energies indicated above, give $1.3 \times 10^{9}$ and $1.1 \times$ $10^{9} \mathrm{~mol}^{-1} \mathrm{dm}^{3} \mathrm{~s}^{-1}$, respectively, which should be compared with the observed rate $(1.4 \pm 0.1) \times 10^{9} \mathrm{~mol}^{-1} \mathrm{dm}^{3} \mathrm{~s}^{-1}$. The calculated branching ratio at this temperature is $\varphi=0.54$. The underestimation of $\varphi$ is probably due to an overestimation of the $\mathrm{H}$ bond energy. For example, with $D_{\mathrm{XY}}=1.3 \mathrm{kcal} \mathrm{mol}^{-1}, \varphi$ increases to 0.76 . The competitiveness of the $\mathrm{Cl}$ abstraction channel results from two factors. Firstly, we have neglected the $X Y$ repulsion of the $V_{X Y}(n)$ Morse curve, calculated with the LS potential and included in Equation (4), because the LS potential is not calibrated for the transfer of atoms involved in much 
longer bonds than hydrogen. For this halogen atom transfer, Equation (4) is replaced by Equation (10):

$$
\begin{aligned}
& V(n)=(1-j) V_{\mathrm{HX}}(1-j)+j V_{\mathrm{HY}}(j)+k \Delta V^{0}-D_{\mathrm{XY}} \\
& \text { for } n^{*}{ }_{\mathrm{HX}}<n<n^{*}{ }_{\mathrm{HY}}
\end{aligned}
$$

Secondly, the $\mathrm{Cl}$ abstraction involves the breaking and formation of weaker bonds, which is reflected both in the bond dissociation energies and vibrational frequencies of the $\mathrm{Cl}-\mathrm{O}$ and $\mathrm{Cl}-\mathrm{Cl}$ bonds. The harmonic force constants for these bonds are much lower than those of the $\mathrm{O}-\mathrm{H}$ and $\mathrm{H}-\mathrm{Cl}$ bonds, and lead to a lower energy barrier. ${ }^{[63]}$

\subsection{Proton-Transfer Barriers}

Ion-molecule $\mathrm{H}$-bonded complexes transfer a proton rather than a hydrogen atom between the precursor and successor complexes: $\mathrm{Y}^{-}+\mathrm{HX} \rightarrow \mathrm{Y}^{-} \ldots \mathrm{HX} \rightarrow \mathrm{YH} \cdots \mathrm{X}^{-} \rightarrow \mathrm{YH}+\mathrm{X}^{-}$. The prototype system is $\mathrm{H}_{3}{ }^{-}$, which is also the simplest analogue of an $\mathrm{S}_{\mathrm{N}} 2$ reaction with closed-shell reactants. Figure 6 compares the

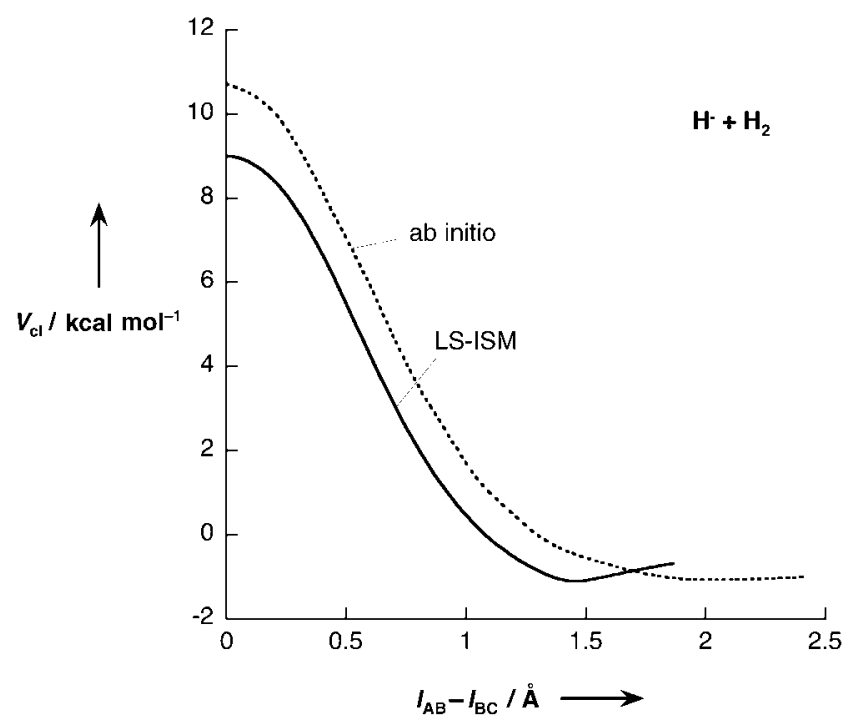

Figure 6. Comparison between LS-ISM and ab initio potentials along the minimum energy path for the reaction $\mathrm{H}^{-}+\mathrm{H}_{2}$.

LS-ISM reaction path, using $D_{e}=1.10 \mathrm{kcal} \mathrm{mol}^{-1}$, with the classical potential that fits accurate ab initio calculations. ${ }^{[48]}$ In this proton transfer, just as in the $\mathrm{Cl}$-atom transfer discussed above, we neglected the $\mathrm{XY}$ repulsion of the $V_{\mathrm{XY}}(n)$ Morse curve and replaced Equation (4) by Equation (10). We emphasize again that the $X Y$ repulsion originating from the LS potential is only appropriate for $\mathrm{H}$-atom transfers. The presence of a proton between $X$ and $Y$ quenches the repulsion associated with the overlap of their electronic orbital that is expressed by the repulsion term $V_{\mathrm{XY}}(n)$ from $n_{\mathrm{HX}}{ }^{*}$ to $n^{\neq}$, and from $n^{\neq}$to $n_{\mathrm{HY}}{ }^{*}$.

If $\mathrm{X}$ is a halogen or $\mathrm{OH}$, the bond orders given by Equation (2) are slightly larger than 0.5 . In such cases, the LS potential remains attractive in the region of the reaction coordinate where $n^{\neq}=0.5$, and it is not possible to find a central barrier separating the $(\mathrm{X} \cdots \mathrm{H}-\mathrm{X})^{-}$and $(\mathrm{X}-\mathrm{H} \cdots \mathrm{X})^{-}$complexes. All other systems addressed in this work have a central barrier flanked by two minima.

The proton-transfer barrier expressed by Equation (10) can be calculated with the usual parameters of ISM. The reaction path shown in Figure 6 was obtained with $m=1$, that is, the electronic factor was assumed to be identical to that of the ISM reference reaction, $\mathrm{H}+\mathrm{H}_{2} \rightarrow \mathrm{H}_{2}+\mathrm{H}^{[28]}$ The ability to predict energy barriers with ISM relies on the calculation of $m$ from the electronic properties of reactants and products. Equation (7) does a remarkable job in calculating $m$ for atom-transfer reactions. The same parameter must also account for the electron flow in the transition states of proton transfers. The valence bond picture of such transition states reveals that the height of the barrier depends on the energy of the structure $\mathrm{Y}^{-} . . \mathrm{H}^{+} . . \mathrm{X}^{-}$, and that its energy is stabilized by the electrostatic interaction between the central proton and the $X$ and $Y$ groups. ${ }^{[23]} \mathrm{Ab}$ initio calculations also support the stabilization of the transition state by an increase in the charge on the inflight hydrogen in the transition state, or equivalently, as reaction termini $\mathrm{X}$ and $\mathrm{Y}$ become more electronegative. ${ }^{[25]}$

The electron affinity plays the role of the electronegativity in the electronic parameter $m$ employed for atom transfers. However, proton transfers involve ionic species and have enhanced polar effects. This should be particularly notorious when $X$ and $Y$ have significant electron affinities, and the dependence of $m$ on $E_{\mathrm{A}}$ should be larger than that calculated with Equation (7) for atom transfers. Figure 7 illustrates the symmetrical barriers of proton transfers between anionic species calculated with $m=1$ for $\mathrm{CH}_{3}{ }^{-}$and $\mathrm{SiH}_{3}{ }^{-}$, and with $m=2$ for $\mathrm{PH}_{2}{ }^{-}, \mathrm{HCC}^{-}$, $\mathrm{NH}_{2}^{-}, \mathrm{SH}^{-}$, and $\mathrm{NC}^{-}$. The lower value of $m$ was selected to reflect the low electron affinity of $\mathrm{CH}_{3}$ and its inability to induce a significant polar effect, and to reflect the reversed polarity of the $\mathrm{Si}-\mathrm{H}$ bond relative to that of the proton-transfer transition state. Additionally, we did not include the $\left(\mathrm{SiH}_{3}{ }^{-} \ldots \mathrm{SiH}_{4}\right) \mathrm{com}-$ plex in the reaction coordinate because it did not have the geometry of a $\mathrm{H}$ bond. ${ }^{[22]}$ The higher value of $m$ reflects the expected increase from 1.2 to 1.7 given by Equation (7) for all the other systems; this was also employed to describe $\mathrm{N}, \mathrm{O}$, and $\mathrm{S}$ acids in the seminal application of ISM to proton-transfer reactions, because it corresponds to a bond order of unity for the $\mathrm{Y}^{-} . . \mathrm{H}^{+}$and $\mathrm{H}^{+} . . \mathrm{X}^{-}$fragments at the transition state. ${ }^{[30]}$

As mentioned above, the internal barrier diminishes with the strength of the hydrogen bond and with the increase of $m$ from one to two. However, we can also see that $m$ and $D_{\mathrm{XY}}$ remain approximately constant in the series $\mathrm{Y}=\mathrm{HCC}^{-}, \mathrm{NH}_{2}{ }^{-}$, and $\mathrm{SH}^{-}$, but the barrier heights decrease. The same trend was observed in ab initio calculations. Figure 7 shows that this trend is related to the similarity between the geometry of the $\mathrm{H}$-bonded complex and that of the transition state. When the $\mathrm{HX}$ and HY bond lengths in the complex approach those of the transition state, the barrier tends to zero. This effect is also apparent in the increase of $n_{\mathrm{HY}}^{*}$ from 0.21 to 0.45 in the series $\mathrm{Y}=\mathrm{HCC}^{-}, \mathrm{NH}_{2}^{-}$, and $\mathrm{SH}^{-}$, and is the reason why the systems where $\mathrm{Y}=\mathrm{OH}, \mathrm{F}, \mathrm{Cl}, \mathrm{Br}$, and I have a single well.

Figure 8 shows that the classical internal barriers for proton transfer given by LS-ISM and ab initio calculations ${ }^{[22,24]}$ are in 


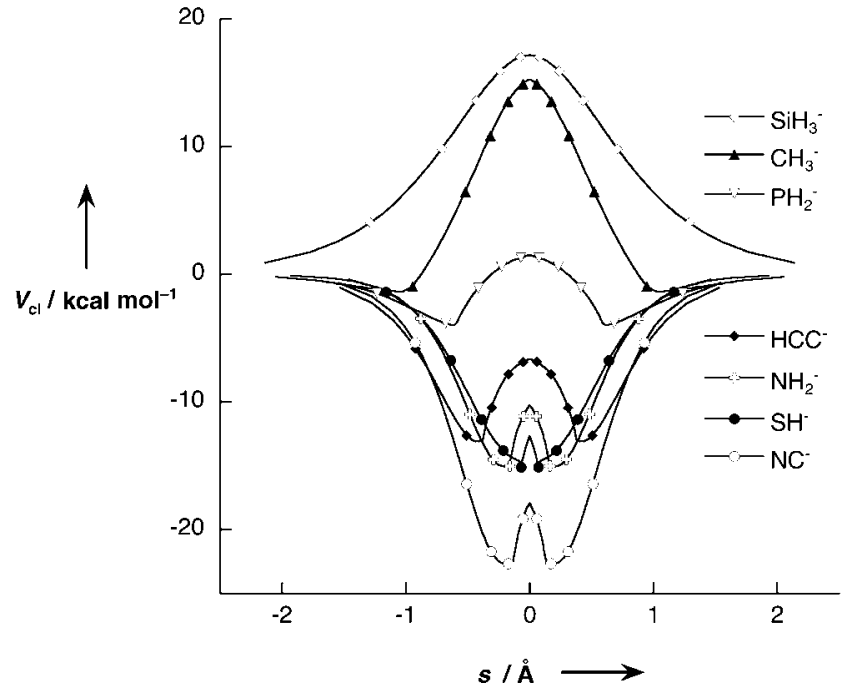

Figure 7. Classical energy profiles of the symmetrical proton transfers involving the anions shown in the figure. The $\mathrm{H}$-binding energies were taken from Table 1.

good agreement. According to the LS-ISM reaction path, the formation of a strong hydrogen-bonded complex brings the structure of the reactants close to that of the transition state and substantially reduces the reaction barrier. Strong hydrogen bonds can be regarded as incipient proton transfers.

Proton-transfer barriers of larger systems can be calculated without additional labor; for example, from the reaction efficiency of the gas-phase proton transfer from toluene to the benzyl anion and RRKM simulation, Han and Brauman obtained a difference of $\Delta E_{\text {dif }}=-5.0 \pm 0.4 \mathrm{kcal} \mathrm{mol}^{-1[76]}$ between the proton-transfer transition state and the reactants at infinite separation. These authors used binding energies of $D_{\mathrm{XY}}=$ $12 \mathrm{kcal} \mathrm{mol}^{-1}$ for this dimer around cluster ions but cautioned that the binding energy "in the $\mathrm{C}_{6} \mathrm{H}_{5} \mathrm{CH}_{2}^{-} \cdot \mathrm{C}_{6} \mathrm{H}_{5} \mathrm{CH}_{3}$ complex is

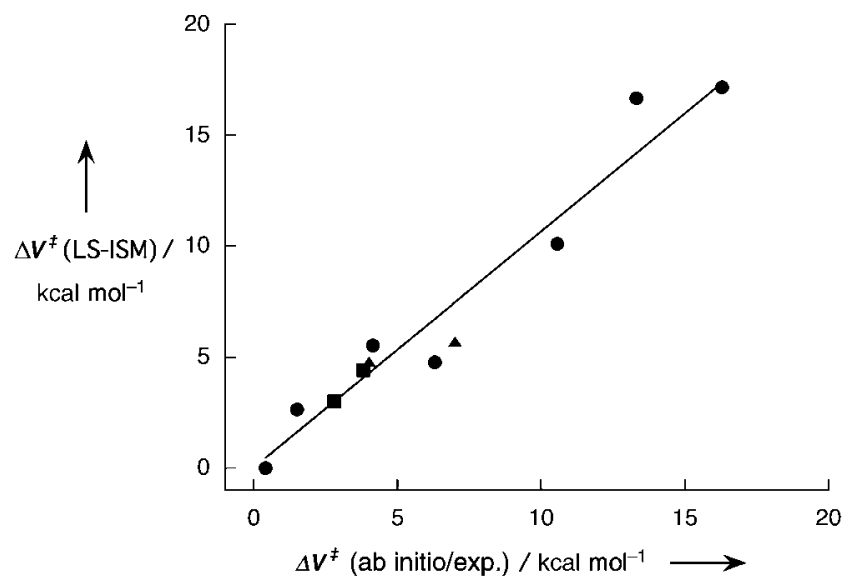

Figure 8. Correlation between the classical internal barrier heights of LS-ISM and $a b$ initio calculations at the QCISD $(T) / 6-311+G(d, p) / / M P 2 / 6-31+G(d, p)$ level (O). Not included in the correlation is the comparison with the adiabatic $\mathrm{G} 2+$ calculations ( $\square$ ) and with the experimental activation energies of the $\mathrm{C}_{6} \mathrm{H}_{5} \mathrm{CH}_{2}^{-} \cdot \mathrm{C}_{6} \mathrm{H}_{5} \mathrm{CH}_{3}$ and $3-\mathrm{CF}_{3} \mathrm{C}_{6} \mathrm{H}_{4} \mathrm{CH}_{2}^{-} \cdot 3-\mathrm{CF}_{3} \mathrm{C}_{6} \mathrm{H}_{4} \mathrm{CD}_{3}$ systems ( $\mathbf{\Delta}$ ). likely to be less than $12 \mathrm{kcalmol}^{-1}$ due to the low dipole moment of toluene and the delocalized charge in benzyl anion". Using the LS-ISM potential with $D_{X Y}=11 \mathrm{kcal} \mathrm{mol}^{-1}$, we obtained $\Delta V_{\text {ad }}{ }^{\neq}=5.7 \mathrm{kcal} \mathrm{mol}^{-1}$ for this proton transfer, that is, $\Delta E_{\text {dif }}=-5.3 \mathrm{kcal} \mathrm{mol}^{-1}$. A second degenerate reaction studied by these authors: $3-\mathrm{CF}_{3} \mathrm{C}_{6} \mathrm{H}_{4} \mathrm{CH}_{2}{ }^{-}+3-\mathrm{CF}_{3} \mathrm{C}_{6} \mathrm{H}_{4} \mathrm{CD}_{3} \rightarrow$ $3-\mathrm{CF}_{3} \mathrm{C}_{6} \mathrm{H}_{4} \mathrm{CH}_{2} \mathrm{D}+3-\mathrm{CF}_{3} \mathrm{C}_{6} \mathrm{H}_{4} \mathrm{CD}_{2}^{-}$gave $\Delta E_{\text {dif }}=-8.0 \pm 0.1 \mathrm{kcal}$ $\mathrm{mol}^{-1}$. With the same data as for toluene and the benzyl anion, except for $D_{\mathrm{XY}}=12 \mathrm{kcalmol}^{-1}$, we obtain $\Delta E_{\text {dif }}=$ $-7.2 \mathrm{kcal} \mathrm{mol}^{-1}$. The difference between internal barriers of these toluene molecules and benzyl anions can be ascribed to the binding energies in the corresponding complexes.

These calculations clearly show that gas-phase proton-transfer reactions, which involve charge-localized and delocalized carbanions, have substantial barriers-as do their counterparts in solution too. The slowness of proton transfers to and from carbon atoms in solution is an intrinsic property of the reactants.

\section{Conclusions}

The combination of the LS potential with ISM leads to reaction paths that accurately represent the energies and geometries of precursor complexes and transition states in atom and proton transfers taking place in $\mathrm{H}$-bonded systems. Such reaction paths are calculated using thermodynamic, spectroscopic, structural, and electronic information on reactants and products, and the $\mathrm{H}$-bond energies. Weak $\mathrm{H}$ bonds $\left(D_{\mathrm{XY}}<5 \mathrm{kcal}\right.$ $\mathrm{mol}^{-1}$ ) between radicals and molecules lead to thinner $\mathrm{H}$-atom transfer barriers and enhanced tunneling corrections. Strong $\mathrm{H}$ bonds $\left(D_{\mathrm{XY}}>10 \mathrm{kcal} \mathrm{mol}^{-1}\right)$ between anions and molecules in the gas phase lead to complexes with structures resembling those of the corresponding proton-transfer transition states, and significantly decrease the proton-transfer barriers. However, the proton-transfer barriers that involve carbanions in the gas phase remain substantial and should also play a role in the rates of the corresponding proton transfers in solution.

\section{Computational Methods}

The Lippincott-Schroeder (LS) potential is expressed as the sum of four terms [Eq. (11)]:

$V_{\mathrm{LS}}=V_{\mathrm{HX}}+V_{\mathrm{HY}}+V_{\text {rep }}+\mathrm{V}_{\mathrm{el}}$

The first two terms represent covalent interactions and have the form presented in Equations (12a) and (12b):

$V_{\mathrm{HX}}=D_{\mathrm{HX}}[1-\exp (-\alpha)]$

$V_{\mathrm{HY}}=D_{\mathrm{HY}^{+}}[1-\exp (-\beta)]-D_{\mathrm{HY}^{+}}$

where $D$ is the bond-dissociation energy of the unperturbed $\mathrm{HX}$ and $\mathrm{HY}^{+}$bonds; $\alpha$ and $\beta$ are defined as shown in Equations (13a) and (13b), with $\kappa_{\mathrm{HX}}, \kappa_{\mathrm{HY}+}$ defined as in Equations (14a) and (14b):

$\alpha=\frac{\kappa_{\mathrm{HX}}\left(I_{\mathrm{HX}}-I_{\mathrm{HX}, \mathrm{eq}}\right)^{2}}{2 I_{\mathrm{HX}}}$ 
$\beta=\frac{\kappa_{\mathrm{HY}^{+}}\left(I_{\mathrm{HY}^{+}}-I_{\mathrm{HY}^{+}, \mathrm{eq}}\right)^{2}}{2 I_{\mathrm{HY}}}$

$\kappa_{\mathrm{HX}}=f_{\mathrm{HX}} I_{\mathrm{HX}, \mathrm{eq}} / D_{\mathrm{HX}}$

$\kappa_{\mathrm{HY}^{+}}=f_{\mathrm{HY}^{+}} l_{\mathrm{HY}^{+}, \mathrm{eq}} / D_{\mathrm{HY}^{+}}$

In these expressions, I (or $f$ ) are the bond lengths (or harmonic force constants) of the unperturbed $\mathrm{HX}$ and $\mathrm{HY}^{+}$bonds. The data pertaining to the unperturbed $\mathrm{HX}$ bond are usually known. For the unperturbed $\mathrm{HY}^{+}$bond, Lippincott and Schroeder introduced the approximation presented in Equation (15), and showed that the parameter $g$ is transferable to all $\mathrm{Y} \cdot \ldots \mathrm{H}-\mathrm{X}$ systems, $g=1.45$ :

$\kappa_{\mathrm{H}^{+}}=g \kappa_{\mathrm{HX}}$

Equation (16) refers to another assumption:

$D_{\mathrm{HX}^{+}}=D_{\mathrm{HY}} / g$

which, with the approximation that $I_{\mathrm{HY}+} \approx I_{\mathrm{HY}}$ provides all the relations necessary to calculate the covalent contributions from the unperturbed $\mathrm{HX}$ and $\mathrm{HY}^{+}$bonds.

The repulsive term was expressed as a negative exponential and the electrostatic one as a negative power of the $\mathrm{XY}$ distance, $I_{\mathrm{XY}}$ Both these terms involve empirical constants. They were modified to reduce the number of constants, and Equation (17) was obtained:

$V_{\text {rep }}+V_{\text {el }}=A\left[\exp \left(-b I_{\mathrm{XY}}\right)+\frac{I_{\mathrm{XY}}^{*}}{2 I_{\mathrm{XY}}} \exp \left(-b I_{\mathrm{XY}}^{*}\right)\right]$

where $I_{\mathrm{XY}}^{*}$ is the $\mathrm{XY}$ distance at which the LS attains its minimum. From the first derivative of the LS potential, Equation (18) shows that:

$A=\frac{D_{\mathrm{HY}^{+}} \kappa_{\mathrm{HY}^{+}}}{2}\left[1-\left(\frac{I_{\mathrm{HY}^{+}}}{I^{*}{ }_{\mathrm{XY}}-I_{\mathrm{XY}}}\right)^{2}\right] \exp (-\beta) / \exp \left(-b I_{\mathrm{XY}}{ }^{*}\right)\left(b-1 / 2 I^{*}{ }_{\mathrm{XY}}\right)$

The only parameter that remains to be fitted to the experimental data is the repulsion constant $b$. Lippincott and Schroeder chose the value $b=4.8 \AA$, and this value was also used in this work.

Another important quantity in the LS potential is the force constant of the $X Y$ bond. This can be obtained from the second derivative of the potential [Eqs. (19a) and (19b)]:

$f_{\mathrm{XY}}=B+A \exp \left(-b I_{\mathrm{XY}}^{*}\right) \frac{\left(b I_{\mathrm{XY}}^{*}\right)^{2}-1}{\left(I_{\mathrm{XY}}^{*}\right)^{2}}$

$B=\frac{D_{\mathrm{HY}^{+}} \kappa_{\mathrm{HY}^{+}}}{I_{\mathrm{HY}^{+}}} \exp (-\beta)\left[\left(I_{\mathrm{HY}}, \mathrm{eq}\right)^{2}-\frac{\beta}{2}\left(I_{\mathrm{HY}^{+}}+I_{\mathrm{HY}^{+}, \mathrm{eq}}\right)^{2}\right]$

The importance of this force constant lies on its relation with the $X Y$ vibrational frequency, which is defined as shown in Equation (20):

$\omega_{\mathrm{XY}}=\frac{1}{2 \pi} \sqrt{\frac{f_{\mathrm{XY}}}{\mu_{\mathrm{XY}}}}$

We correct the $\mathrm{H}$-bond energies, $D_{\mathrm{XY}}$ for the zero-point energy of the $X Y$ vibration by calculating $\omega_{\mathrm{XY}}$ from $D_{\mathrm{XY}}$ to obtain a first approximation to the zero-point energy, and then recalculating the LS potential and its properties with $D_{\mathrm{XY}}+\mathrm{ZPE}$. The $D_{\mathrm{XY}}$ values presented in Table 1 are measured enthalpies of formation of $\mathrm{H}$ bonded complexes and were treated with this procedure. The other values were taken from ab initio calculations and are more appropriately called bond-dissociation energies at $0 \mathrm{~K}\left(D_{0}\right)$ or electronic binding energies $\left(D_{\mathrm{e}}\right)$. We applied the zero-point energy correction to the former, but not to the latter.

The relations above show that, knowing either $D_{\mathrm{XY}}$ or $\omega_{\mathrm{XY}}$ it is possible to calculate the other parameters and obtain a Morse curve [Eq. (21)] that represents the formation of the $\mathrm{Y} \cdots \mathrm{H}-\mathrm{X}$ bond:

$V_{\mathrm{XY}}=D_{\mathrm{XY}}\left\{1-\exp \left[-\beta_{\mathrm{HX}}\left(I_{\mathrm{XY}}-I^{*} \mathrm{XY}\right)\right]\right\}$

This Morse curve was added to the Morse curves representing the $\mathrm{HX}$ and HY bonds and included in the reaction coordinate of the ISM [Eq. (4)].

Zero-point energies were added along classical reaction paths using a procedure described elsewhere, ${ }^{[28]}$ and vibrationally adiabatic paths were obtained. The highest energy along the vibrationally adiabatic path is identified as the vibrationally adiabatic barrier, $\Delta^{\mp} V_{\text {add }}$. The atom- or proton-transfer rates of systems with $\Delta^{\ddagger} V_{\text {ad }}>0$ can be calculated with the transition-state theory and the semiclassical correction for tunneling, as described by the ISM/sc-TST method. ${ }^{[28]}$ ISM/sc-TST calculations require empirical information on bond-dissociation energies, electrophilicity indices, bond lengths, and vibration frequencies of the reactive bonds. This data was recently presented elsewhere ${ }^{[28]}$ and was used in this work. The only additional parameter required by LS-ISM/sc-TST calculations, is the strength of the hydrogen bond, $D_{\mathrm{XY}}$ and its value is given in Tables 1 and 2.

In earlier applications of the ISM, the electrophilicity index proposed by Parr ${ }^{[67]}$ was kept constant along the reaction coordinate. Here, we refine our approach and consider that $m$ increases from unity in the reactants to its maximum value in the transition state [Eq. (10)] and then returns to unity in the products [using a switching function similar to that employed for ZPE variation along the reaction path, ${ }^{[28]}$ see Eqs. (22a)-(22c)]:

$y(n)=\cosh \left[\frac{I_{\mathrm{BC}}}{I_{\mathrm{BC}}+I_{\mathrm{AB}}} \cdot \frac{\ln \left(n^{\neq}\right)}{\ln (2 n)}\right]$ for $n<n^{\neq}$

$y(n)=0 \quad$ for $n=n^{*}$

$y(n)=\cosh \left[\frac{I_{\mathrm{BC}}}{I_{\mathrm{BC}}+I_{\mathrm{AB}}} \cdot \frac{\ln \left(1-n^{*}\right)}{\ln (2(1-n))}\right]$ for $n>n^{\neq}$

\section{Acknowledgements}

We thank FCT (Portugal) and FEDER (European Union) for financial support through project no. POCTI/QUI/47267/2002. MB thanks the financial support by FCT through grant $B D / 1332 /$ 2000. LGA wishes to thank the European Science Foundation (ULTRA Programme) for a grant.

Keywords: activation parameters - hydrogen bonds ionization potentials - semiempirical calculations - transition states

[1] J. C. Hansen, J. S. Francisco, ChemPhysChem 2002, 3, 833

[2] W. W. Cleland, M. M. Kreevoy, Science 1994, 264, 1887.

[3] A. Novak, Struct. Bonding 1974, 18, 177.

[4] J. Emsley, Chem. Soc. Rev 1980, 9, 91.

[5] F. Hibbert, J. Emsley, Adv. Phys. Org. Chem. 1990, 26, 255.

[6] M. Rozenberg, G. Shoham, I. Reva, R. Fausto, Spectrochim. Acta 2004 A55, 1585. 
[7] C. J. T. de Grotthuss, Ann. Chim. 1806, 58, 54

[8] R. P. Bell, The Proton in Chemistry, Methuen \& Co. Ltd., London, 1959.

[9] M. Eigen, Angew. Chem. 1965, 77; Angew. Chem. Int. Ed. Engl. 1965, 3, 1.

[10] S. Scheiner, Annu. Rev. Phys. Chem. 1994, 45, 23.

[11] D. Marx, M. E. Tuckerman, J. Hutter, M. Parrinello, Nature 1999, 397, 601.

[12] Ultrafast Hydrogen Bonding Dynamics and Proton Transfer Processes in the Condensed Phase (Eds.: T. Elsaesser, H. J. Bakker), Kluwer, Dordrecht, 2002

[13] E. R. Lippincott, R. Schroeder, J. Chem. Phys. 1955, 23, 1099.

[14] R. Schroeder, E. R. Lippincott, J. Phys. Chem. 1957, 61, 921.

[15] C. Reid, J. Chem. Phys. 1959, 30, 182.

[16] J. N. Spencer, G. J. Casey Jr., J. Buckfelder, H. D. Schreiber, J. Phys. Chem. 1974, 78, 1415.

[17] P. Gilli, V. Bertolasi, V. Ferretti, G. Gilli, J. Am. Chem. Soc. 1994, 116, 909.

[18] S. J. Grabowski, T. M. Krygowski, Tetrahedron 1998, 54, 5683.

[19] S. Scheiner, J. Mol. Struct. (Theochem.) 1994, 307, 65.

[20] S. J. Grabowski, J. Phys. Chem. 2001, 105, 10739.

[21] I. V. Alabugin, M. Manoharan, S. Peabody, F. Weinhold, J. Am. Chem. Soc. 2003, 125, 5973

[22] S. Gronert, J. Am. Chem. Soc. 1993, 115, 10258.

[23] W. Wu, S. Shaik, W. H. Saunders Jr., J. Phys. Chem. 2002, 106, 11616.

[24] S. Gronert, C. Kimura, J. Phys. Chem. 2003, 107, 8932.

[25] J. R. Keeffe, S. Gronert, M. E. Colvin, N. L. Tran, J. Am. Chem. Soc. 2003, 125, 11730.

[26] A. Halkier, W. Klopper, T. Helgaker, P. Jørgensen, P. R. Taylor, J. Chem. Phys. 1999, 111, 9157.

[27] W. Klopper, J. G. C. M. van Duijneveldt-van de Rijdt, F. B. van Duijneveldt, PCCP 2000, 2, 2227.

[28] L. G. Arnaut, A. A. C. C. Pais, S. J. Formosinho, M. Barroso, J. Am. Chem Soc. 2003, 125, 5236.

[29] B. C. Garrett, D. G. Truhlar, J. Phys. Chem. 1979, 83, 2921.

[30] S. J. Formosinho, J. Chem. Soc. Perkin Trans. 2 1987, 61

[31] L. G. Arnaut, S. J. Formosinho, J. Phys. Chem. 1988, 92, 685.

[32] L. G. Arnaut, S. J. Formosinho, J. Photochem. Photobiol. A: Chem. 1993, $75,1$.

[33] D. D. Nelson Jr., G. T. Fraser, W. Klemperer, J. Chem. Phys. 1985, 83, 6201.

[34] E. H. T. Olthof, A. van der Avoird, P. E. S. Wormer, J. Chem. Phys. 1994, 101,8430 .

[35] L. Masgrau, A. Gonzalez-Lafonf, J. M. Lluch, J. Phys. Chem. A 1999, 103, 1044.

[36] P. D. Cooper, H. G. Kjaergaard, V. S. Langford, A. J. McKinley, T. I. Quickenden, D. P. Schofield, J. Am. Chem. Soc. 2003, 125, 6048.

[37] M. R. Hand, C. F. Rodriguez, I. H. Williams, G. G. Balin-Kurti, J. Phys. Chem. A 1998, 102, 5958.

[38] H. S. Gutowsky, C. Chuang, J. D. Keen, T. D. Klots, T. Emilsson, J. Chem. Phys. 1985, 83, 2070.

[39] M. Bittererová, S. Biskupic, Chem. Phys. Lett. 1999, 299, 145.

[40] M. J. Elrod, R. J. Saykally, J. Chem. Phys. 1995, 103, 921.

[41] I. Bakó, G. Pálinkás, J. Mol. Struct. 2002, 594, 179.

[42] A. Bizzarri, S. Stolte, J. Reuss, J. G. C. M. van Duijneveldt-van de Rijdt, F. B. van Duijneveldt, Chem. Phys. 1990, 143, 423.

[43] J. Espinosa-García, A. M. Cruz, Chem. Phys. Lett. 2003, 377, 613.

[44] M. A. Vincent, J. N. L. Connor, M. S. Gordon, S. C. Schatz, Chem. Phys. Lett. 1993, 203, 415 .
[45] G. Oliveira, C. E. Dykstra, Chem. Phys. Lett. 1995, 243, 158.

[46] P. G. Sennikov, D. A. Raldugin, V. E. Shkrunin, K. G. Tokhadze, J. Mol. Struct. 1990, 219, 203

[47] H. H. Michels, J. A. Montgomery Jr., Chem. Phys. Lett. 1987, 139, 535.

[48] J. Stärck, W. Meyer, Chem. Phys. 1993, 176, 83.

[49] NIST Chemistry WebBook, NIST Standard Reference Database Number 69 (Eds.: P. J. Linstrom, W. G. Mallard), National Institute of Standards and Technology, Gaithersburg MD, 20899, 2003 (http://webbook.nist.gov).

[50] M. Ardon, A. Bino, W. G. Jackson, Polyhedron 1987, 6, 181.

[51] S. Kawahara, T. Uchimaru, K. Taira, Chem. Phys. 2001, 273, 207.

[52] L. W. Schroeder, J. A. Ibers, J. Am. Chem. Soc. 1966, 88, 2601.

[53] L. W. Schroeder, J. A. Ibers, Inorg. Chem. 1968, 7, 594.

[54] J. M. Reddy, K. Knox, M. B. Robin, J. Chem. Phys. 1964, 40, 1082.

[55] R. M. Bentwood, A. J. Barnes, W. J. Orville-Thomas, J. Mol. Spectrosc. 1980, 84, 391.

[56] T. R. Dyke, J. Chem. Phys. 1977, 66, 492.

[57] L. Fredin, B. Nelander, G. Ribbegerd, J. Chem. Phys. 1977, 66, 4065.

[58] G. S. Tschumper, M. L. Leininger, B. C. Hoffman, E. F. Waleev, H. F. Schaefer, III, M. J. Quack, J. Chem. Phys. 2002, 116, 690.

[59] V. F. DeTuri, M. A. Su, K. M. Ervin, J. Phys. Chem. A 1999, 103, 1468.

[60] F. F. Muguet, G. W. Robinson, M. P. Bassez-Muguet, J. Chem. Phys. 1995, $102,3655$.

[61] L. Pauling, J. Am. Chem. Soc. 1947, 69, 542

[62] A. A. C. C. Pais, L. G. Arnaut, S. J. Formosinho, J. Chem. Soc. Perkin Trans. 2 1998, 2577

[63] L. G. Arnaut, A. A. C. C. Pais, S. J. Formosinho, J. Mol. Struct. 2001, 563/ $564,1$.

[64] H. S. Johnston, Adv. Chem. Phys. 1960, 3, 131.

[65] H. S. Johnston, C. Parr, J. Am. Chem. Soc. 1963, 85, 2544.

[66] A. J. C. Varandas, S. J. Formosinho, J. Chem. Soc. Faraday Trans. 2 1986, 82, 953.

[67] R. G. Parr, L. V. Szentpály, S. Liu, J. Am. Chem. Soc. 1999, 121, 1922.

[68] R. Steckler, G. M. Thurman, J. D. Watts, R. J. Bartlett, J. Chem. Phys. 1997, $106,3926$.

[69] NIST Chemical Kinetics Database on the Web, NIST Standard Reference Database 17, Version 7.0, Release 1.1, National Institute of Standards and Technology, 2000 (http://kinetics.nist.gov/index.php).

[70] A. S. Pine, B. J. Howard, J. Chem. Phys. 1986, 84, 590.

[71] W. B. Zeimen, J. Klos, G. C. Groenenboom, A. van der Avoird, J. Phys. Chem. A 2003, 107, 5110.

[72] J. Hägele, K. Lorenz, D. Rhäsa, R. Zellner, Ber. Bunsenges. Phys. Chem. $1983,87,1023$.

[73] L. M. Loewenstein, J. G. Anderson, J. Phys. Chem. 1984, 88, 6277.

[74] L. Wang, J.-Y. Liu, Z.-S. Li, X.-R. Huang, C.-C. Sun, J. Phys. Chem. A 2003, $107,4921$.

[75] A. Kukui, J. Roggenbuck, R. N. Schindler, Ber. Bunsenges. Phys. Chem. $1997,101,281$

[76] C.-C. Han, J. I. Brauman, J. Am. Chem. Soc. 1989, 111, 6491.

Received: June 16, 2004

Revised: October 28, 2004

Published online on January 13, 2005 